Provided for non-commercial research and education use. Not for reproduction, distribution or commercial use.

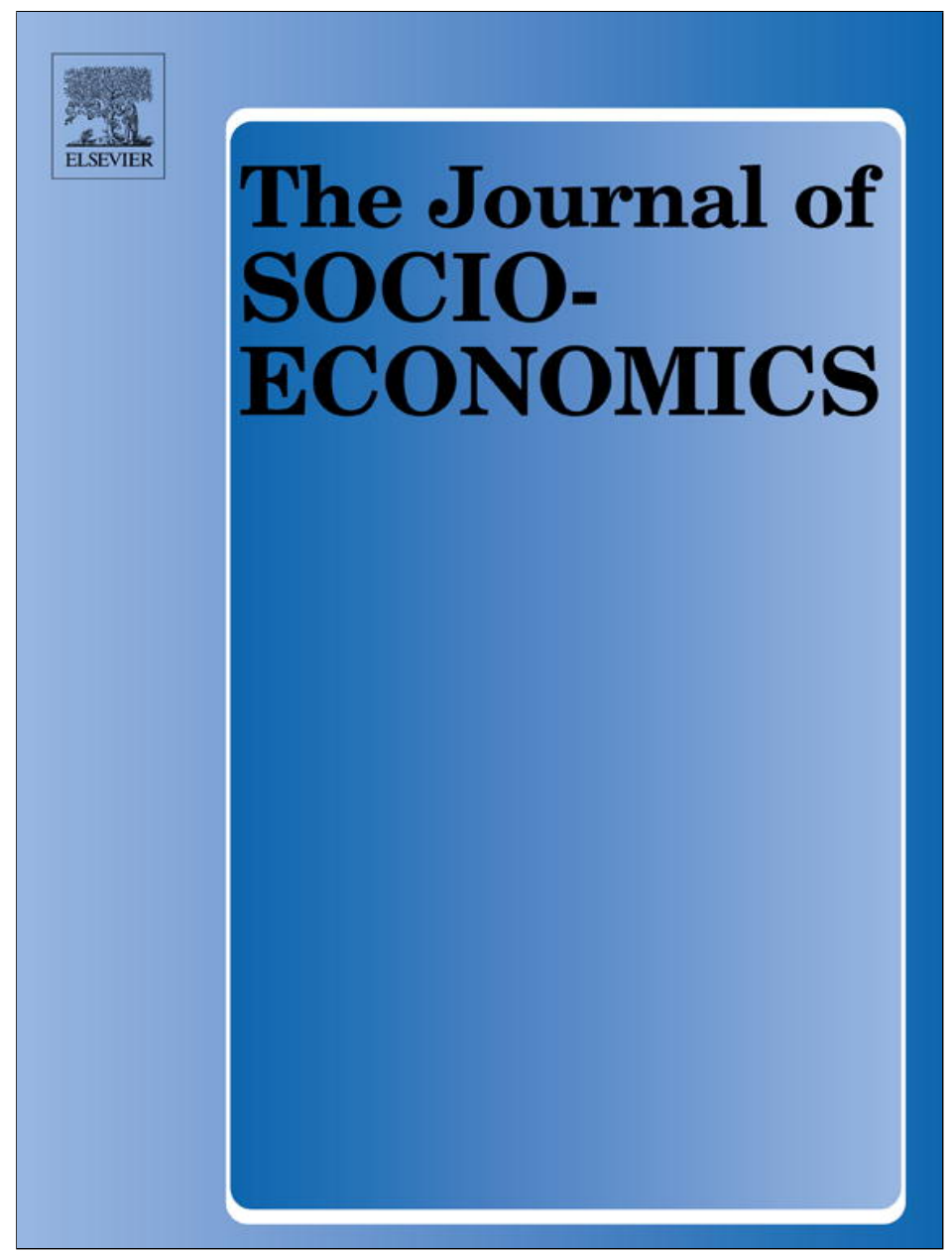

(This is a sample cover image for this issue. The actual cover is not yet available at this time.)

This article appeared in a journal published by Elsevier. The attached copy is furnished to the author for internal non-commercial research and education use, including for instruction at the authors institution and sharing with colleagues.

Other uses, including reproduction and distribution, or selling or licensing copies, or posting to personal, institutional or third party websites are prohibited.

In most cases authors are permitted to post their version of the article (e.g. in Word or Tex form) to their personal website or institutional repository. Authors requiring further information regarding Elsevier's archiving and manuscript policies are encouraged to visit:

http://www.elsevier.com/copyright 


\title{
Why do spouses hide income?
}

\author{
Hazel Jean L. Malapit* \\ The World Bank, 1818 H St NW, Washington, DC 20433, United States
}

\section{A R T I C L E I N F O}

\section{Article history:}

Received 15 January 2011

Received in revised form 25 February 2012 Accepted 9 April 2012

\section{JEL classification:}

D13

D14

J16

\section{Keywords:}

Intrahousehold allocation

Income pooling

Saving

Bargaining power

\section{Introduction}

It seems obvious that anybody could keep a 'secret stash' of money behind their spouse's back if they wanted to. Even the earliest typologies of money management arrangements in male breadwinner households implicitly allowed for some hiding of income (Pahl, 1983, 1989, 1995). Nevertheless, this aspect of intrahousehold decision making has been overlooked by social scientists because, first, the hiding of income was expected to be small and therefore immaterial, and second, it does not immediately appear to have other important consequences. There is growing evidence, however, that not only is the amount of hidden income substantial in both developed and developing countries, but also that it has broader implications on the way economists conduct household surveys and on the rigor of the empirical analyses that use them. Taking this issue seriously raises a number of questions: Under what conditions do these decisions take place and what incentives do spouses face? What role does bargaining power play? Is there reason to believe that women are more likely than men to hide income, as popular media suggests (Whitaker, 2004)? Are there fundamental differences between, for example, the decision of a Kenyan woman to join a 'secret saving club' (Anderson and Baland, 2002), the decision of a Japanese woman to keep her hesokuri or belly button money (Whitaker, 2004), and the decision of

\footnotetext{
* Tel.: +1 202473 4456; fax: +1 2025223237 .

E-mail addresses: hmalapit@worldbank.org, hmalapit@gmail.com
}

an American woman to open a private bank account (Whitaker, 2004; Allianz, 2006)?

To explore why spouses hide income, this paper proposes a simplified model of intrahousehold decision making where cooperative and noncooperative behavior are not mutually exclusive. This model differs from other noncooperative bargaining models in that each person's decision to cooperate is characterized as a continuous decision variable. This approach allows individuals to choose the optimal share of income they wish to devote towards cooperation, where income is pooled and allocated collectively, and towards noncooperation, where income is allocated independently. Since individuals can choose to contribute less than their full income, the realized gains from cooperation can also vary according to the contributions of each partner. Using the example of joint saving as an area of household cooperation, this model shows how limited autonomy and bargaining power can interact to create incentives for individuals to hide income.

In contrast, intrahousehold allocation models describe the behavior of married couples as either cooperative or noncooperative. Cooperation implies that couples pool all their resources and then jointly decide how these resources are allocated, be it through consensus, Nash bargaining (Manser and Brown, 1980; McElroy and Horney, 1981), or some other form of collective decision making (Chiappori, 1988, 1992, 1997). If cooperation breaks down and divorce is not feasible, ${ }^{1}$ individuals retreat to their fallback

\footnotetext{
${ }^{1}$ Lundberg and Pollak (1993) argue that the noncooperative solution can arise if binding contracts are not enforceable or if transactions and/or monitoring costs overwhelm potential gains from cooperation.
} 
positions given by the noncooperative solution within marriage (for example, see Lundberg and Pollak, 1993; Carter and Katz, 1997; Chen and Wooley, 2001). Noncooperation implies that individuals allocate their own resources according to their personal preferences. Any contributions to household public goods in the absence of cooperation are therefore voluntary, and may be guided by socially accepted gender roles (Lundberg and Pollak, 1993).

This depiction of household decision making has important implications for the collection of financial information in household surveys. Cooperation implies that information is publicly shared within households, while the withholding of information implies noncooperation. ${ }^{2}$ The conventional belief that families are inherently cooperative, or at the very least share information completely even when they do not cooperate, is the rationale for the collection of financial information at the household level. ${ }^{3}$

There is growing evidence, however, that the extent of privately held information missed by conventional household surveys may be substantial. A number of specialized surveys that collect income and other financial information from spouses in separate interviews show that some financial transactions undertaken by individuals were unknown to their partners. For example, data collected by Markus Goldstein and Christopher Udry in Ghana reveal significant differences in what couples know about each other's income and expenditures (Goldstein, 1999). Similarly, Ashraf (2009) finds that 34 percent of husbands in her sample make more money without their wife's knowledge, while 29 percent of wives make more money without their husbands' knowledge. In addition, her randomized field experiment provides evidence that Filipino men prefer to hide extra income when they know that their wives will not find out (Ashraf, 2009). These findings are not unique to developing countries, however. A 2006 Allianz survey of 3183 adults in the United States reveal that 18 percent of women and 9 percent of men keep a 'secret stash' of cash unknown to their spouse (Allianz, 2006).

The prevalence of privately held financial information may suggest that the behavior of married couples is better described by individual-level or noncooperative models. In many cases, however, the hiding of financial information is accompanied by seemingly cooperative behavior. Ashraf (2009) observes that some individuals choose to conceal a portion of their income even while reporting joint control over financial decisions. A similar pattern emerges among Thai and Filipino couples in the 2002 Urban Poor Home Worker Survey (UPHWS), where some individuals report both joint and personal saving accounts. ${ }^{4}$ These studies suggest that cooperative and noncooperative behavior are not necessarily mutually exclusive. Partial or semi-cooperation can be done overtly, where the witheld portion of individual incomes are publicly known within the household, or covertly, where individuals report or disclose only the portion of income or assets that they wish to contribute to the household pool and then conceal the rest. ${ }^{5}$ Such semi-cooperative behavior can be justified using existing household models by assuming that some household decisions are cooperative, while some are noncooperative (Agarwal, 1997;

\footnotetext{
2 Note that under noncooperation, information may or may not be publicly shared within the household. Thus, public information is consistent with both cooperation and noncooperation, while private information strictly implies noncooperation.

3 In a unitary model, one spouse can act as a dictator (benevolent or otherwise), controling all resources and making all the decisions. Thus, complete information can be obtained so long as the benevolent dictator or household head is chosen as the survey respondent.

4 The 2002 UPHWS is a multi-country dataset collected by American University and Cornell University researchers in Bolivia, Ecuador, Thailand and the Philippines. Its credit, savings and decision making modules were collected from husbands and wives privately in separate interviews.

5 An alternative strategy is to report "ghost" expenses or salary deductions,
} referred to in the Tagalog vernacular as kupit (literally, "to pilfer") (Ashraf, 2009).
Katz, 1997). Nevertheless, existing models are unclear on how both cooperative and noncooperative behavior can arise simultaneously within the same types of decisions, e.g., saving, as the evidence suggests.

The possibility that households behave semi-cooperatively reinforces the issues raised by noncooperative household models on traditional survey methodology. Estimation of demand functions that use household income as a regressor can yield biased estimates if surveys measure household income incorrectly by relying on a single household informant. This measurement error is easily corrected if such errors arise randomly. But if the degree to which individuals keep financial information private varies systematically, say with bargaining power or other characteristics, then this measurement error may be endogenous. This endogeneity introduces an additional source of bias for empirical analyses that use household income as a regressor (Ashraf, 2009). The model proposed in this paper demonstrates how cooperating couples can, at the same time, behave noncooperatively, thus providing further theoretical support for the call to collect financial information individually and separately for couples.

The rest of the paper is organized as follows. Section 2 presents a brief survey of related literature on intrahousehold allocation, followed by a description of the general model setup, its application to savings, and a discussion of the implications of limited autonomy in Section 3. Section 4 concludes.

\section{Brief review of related models}

Economists have traditionally described household behavior as unitary. As its name suggests, the unitary model treats the household as if it were a single utility-maximizing agent. In the unitary model, a benevolent dictator or representative agent allocates pooled household income to maximize household welfare. A household may act as one if all of its members has identical or common preferences (Samuelson, 1956), if one member acts like a dictator out of benevolence (Becker, 1981), or if one member acts like a dictator out of their ability to use violence on other members (Alderman et al., 1995).

An important shortcoming of the unitary model is that it is not clear how conflicting preferences within households are resolved. Instead, unitary models portray the household as a harmonious whole, which, ideal as it may be, runs counter to common experience. Becker (1981) addressed this concern through his famous "Rotten Kid Theorem," which demonstrated how dissenting wives defer to their altruistic husbands out of self-interest. This defense of the unitary model was not entirely convincing to many researchers who sought alternative models of household decision making. This led to a new class of collective or joint decision making models that recognize the distinct preferences of individual members but differ primarily in the mechanisms by which families are assumed to resolve their differences.

Two types of collective models have since dominated the literature: Nash cooperative bargaining models, and the sharing-rule approach or Chiappori-type collective models. Manser and Brown (1980) and McElroy and Horney (1981) pioneered the application of a Nash cooperative bargaining framework in the household context. In a Nash cooperative bargaining model, the married couple solves a joint allocation problem to maximize the product of individual gains to cooperation subject to a joint full-income constraint (McElroy, 1997). The division of the utility gains from cooperation therefore varies systematically with members' threat point or fallback position, the level of utility individuals can expect outside the marriage. An important contribution of this line of modeling is that the concept of relative power within the household is made explicit through the fallback positions or outside options, which ultimately determine intrahousehold allocation. McElroy (1990, 
1997) describes these fallback positions as a function of demographic, legal, macroeconomic and other institutional conditions external to the household.

A more general type of collective household model is the sharing-rule approach introduced by Chiappori $(1988,1992,1997)$. In a Chiappori-type collective model, there are no restrictions on how joint decision making takes place, except that the resulting allocations be efficient. Thus, the household behaves as if it were maximizing the weighted sum of individual members' preferences, where the weights or shares reflect the relative bargaining power of individuals (Quisumbing and Maluccio, 2003). The result is that the allocations more closely reflect the preferences of the more powerful household members, consistent with the predictions of the Nash cooperative bargaining models. This model also exhibits the useful property of nesting the unitary model. The household welfare function collapses to a single set of preferences when preferences are common, i.e., the weights do not matter, or when the sharing rule is weighted entirely towards one person's (the dictator's) preferences, i.e., other members' preferences do not matter. This feature facilitated empirical tests of the unitary model, and has led to the accumulation of empirical evidence against it (Alderman et al., 1995).

These non-unitary models have thus refined the picture of the family from a perfectly harmonious unit acting as one, to a diverse collection of individuals whose differences are resolved through the spirit of cooperation. After the negotiations and deliberations are done, in the end, the family acts together. Underlying this view of the household is the assumption that family members are able to make binding agreements to enforce the joint allocation, and that irreconcilable differences lead to divorce or household dissolution. ${ }^{6}$ In other words, without cooperation, there is no household.

While divorce may be the ultimate threat in the context of marital bargaining, there are reasons to expect that marital noncooperation is possible (Lundberg and Pollak, 1993). Divorce may not always be socially acceptable, can entail prohibitive costs and irreversible consequences, and therefore may not be a credible threat, particularly in the negotiation of ordinary household disputes (Lundberg and Pollak, 1993; Bergstrom, 1996). A number of researchers have instead used the noncooperative equilibrium within the marriage, aptly described by Bergstrom (1996) as "harsh words and burnt toast," as the threat point within the Nash bargaining framework (for example, see Lundberg and Pollak, 1993; Carter and Katz, 1997; Chen and Wooley, 2001). In a noncooperative marriage, partners behave independently, pursuing their own personal preferences subject to their own resource constraints, and contributing voluntarily towards the provision of household public goods. Noncooperative bargaining models therefore nest both the cooperative and noncooperative solutions within the same framework. If household members choose to cooperate, they pool all their income and jointly allocate it, as in the cooperative solution. Otherwise, the outcome is a noncooperative marriage given by the Cournot-Nash equilibrium. ${ }^{7}$

Perhaps the most influential among the class of noncooperative bargaining models is the separate spheres model introduced by Lundberg and Pollak (1993). When cooperation breaks down due to prohibitive transactions costs or low expected gains from cooperation, the noncooperative separate spheres equilibrium is

\footnotetext{
${ }^{6}$ Since marital bargaining can be interpreted as a repeated game, the enforceability of the cooperative outcome can be justified using the folk theorem (Pollak, 2005).

7 More recently, researchers have moved towards accommodating more noncooperative behavior within households in other ways. For example, see Konrad and Lommerud (2000), Lundberg and Pollak (2003), Aura (2005), Mazzocco (2007), and Fletschner (2009)
}

characterized by gender specialization in the division of household responsibilities (Lundberg and Pollak, 1993). Thus, each spouse makes independent decisions within his or her own sphere of influence, as defined by socially recognized and accepted gender roles. An important contribution of this model is its explicit attention to the role of traditional gender norms in coordinating behavior within households even in the absence of explicit bargaining. This result is widely corroborated in ethnographic research (Pahl, 1983, 1989, 1995; Benería and Roldán, 1987; Dwyer and Bruce, 1988), as well as in the more recent survey conducted by Goldstein and Udry (1999) in Ghana.

Although noncooperative bargaining models accommodate both cooperative and noncooperative behavior, these outcomes remain mutually exclusive. Therefore, it is unclear how the same types of decisions can appear to be both jointly determined and individually determined. The separate spheres equilibrium can offer more guidance in explaining this phenomenon; what appears to be cooperation may in reality be a voluntary contribution equilibrium shaped by traditional social norms. But because these norms are determined outside the model, further analysis of this outcome within the separate spheres framework is limited. ${ }^{8}$

Alternatively, this paper presents a simplified model of intrahousehold decision making where individuals noncooperatively choose the optimal share of income they wish to devote towards cooperation, where income is pooled and allocated collectively, and towards noncooperation, where income is allocated independently. This approach of modeling some decisions as cooperative and some decisions as noncooperative is in line with more recent semi-cooperative models proposed in the literature. For example, in the conjugal contract model proposed by Carter and Katz (1997), most decisions are assumed to be noncooperative except for transfers between household members, which is the subject of cooperative bargaining. Fletschner (2009) builds on Carter and Katz's (1997) conjugal contract model by specifying transfers of credit between spouses as the subject of bargaining. Another example is the model proposed by Konrad and Lommerud (2000), where they assume that human capital investments are chosen noncooperatively in the first period, while subsequent day-to-day time allocation is chosen cooperatively. Similarly, Lundberg and Pollak (2003) present a model where a couple's initial location decision is chosen noncooperatively, while subsequent decision making proceeds collectively and efficiently. These last two models, in particular, emphasize the inefficiencies that arise from the noncooperative decisions. The semi-cooperative model proposed in this paper, on the other hand, emphasizes how spouses choose their optimal degree of cooperation and its implications on informationsharing within households.

The next section presents the model and derives its implications using the example of joint saving as an area of cooperation within the household.

\section{Model}

Consider a married couple, husband $(h)$ and wife $(w)$, who earn exogenous incomes $Y_{h}>0$ and $Y_{w}>0$, respectively. ${ }^{9}$ The wellbeing of the partners are linked through the joint consumption of household public goods (e.g., a shared dwelling, household

\footnotetext{
${ }^{8}$ See Elster (1989) and Sugden (1989) for a discussion of how norms are established and maintained.

${ }^{9}$ Note that this model is applicable to any two-person household. By assuming that individuals earn exogenous incomes, it is implicitly assumed that wage rates are given and that each individual spends a fixed number of hours in market work. More generally, $Y_{i}$ can be interpreted as some fixed endowment, such as time, land, and other assets.
} 
sanitation, children's well-being, precautionary savings, etc.). In the absence of cooperation, each person can contribute voluntarily towards the provision of household public goods. As Lundberg and Pollak (1993) point out, the standard result is that these public goods will be underprovided under a voluntary contribution equilibrium. ${ }^{10}$

Alternatively, individuals can cooperate by contributing some portion $\theta_{i}$ of their income, $0 \leq \theta_{i} \leq 1, i=h, w$, into a household pot for the provision of household public goods. The proportion $\theta_{i}$ can be interpreted as the degree to which the individual chooses to cooperate with his or her spouse. ${ }^{11}$ Following the collective model, assume that the couple allocates the pooled household income jointly through some unspecified process, as if they were maximizing their weighted preferences where the weights or shares represent their relative bargaining strengths (Chiappori, 1992, 1997; Quisumbing and Maluccio, 2003). The resulting allocation of the pooled household income will more closely reflect the preferences of the more powerful spouse. This process is assumed to yield the efficient level of household public goods. Thus, pooling income and coordinating the individuals' contributions in this way, i.e., cooperation, yields potential gains relative to the voluntary contribution or noncooperative equilibrium.

Formally, the outcome of cooperation is described as follows. Let the (net) gains ${ }^{12}$ from cooperation be represented by the function $G\left(\theta_{h} Y_{h}, \theta_{w} Y_{w}\right) \geq 0$, such that $G\left(0, \theta_{w} Y_{w}\right)=G\left(\theta_{h} Y_{h}, 0\right)=0$. Thus, the case where only one person contributes to the household public good is defined here as noncooperation. If some cooperation does take place, $\theta_{h}>0$ and $\theta_{w}>0$, the couple splits the gains from cooperation $G(\cdot)$ according to an exogenous sharing rule, $0 \leq \mu \leq 1$, which summarizes the extent to which each person's preferences are reflected in the allocation of pooled income. The sharing rule can be interpreted as the reduced form of some unspecified process, and is correlated with the relative bargaining strengths of individuals. This unspecified process could entail some form of bargaining or negotiation, and may also be determined by other external factors like social norms and institutions. Assuming that $\mu$ is the husband's share, the contributions $\theta_{h} Y_{h}$ and $\theta_{w} Y_{w}$ yield a payoff of $\mu G\left(\theta_{h} Y_{h}, \theta_{w} Y_{w}\right)$ for the husband, and $(1-\mu) G\left(\theta_{h} Y_{h}, \theta_{w} Y_{w}\right)$ for the wife.

Any leftover income not pooled remains as discretionary income of the individual, allocated independently without the need to coordinate with one's spouse. This discretionary income may be used for private consumption, private saving, or contributed towards any other household public goods that the couple do not wish to jointly provide. Let the total individual payoff be the weighted sum of the benefits from cooperation and the benefits from the remaining discretionary income:

$$
\begin{aligned}
& \mathrm{H}: \pi_{h}=\delta_{h} \mu G\left(\theta_{h} Y_{h}, \theta_{w} Y_{w}\right)+\left(1-\delta_{h}\right)\left(1-\theta_{h}\right) Y_{h}, \\
& \mathrm{~W}: \pi_{w}=\delta_{w}(1-\mu) G\left(\theta_{h} Y_{h}, \theta_{w} Y_{w}\right)+\left(1-\delta_{w}\right)\left(1-\theta_{w}\right) Y_{w} .
\end{aligned}
$$

\footnotetext{
10 According to Lundberg and Pollak (1993, p. 993): “If individual family members can supply public goods consumed by the entire household, then the noncooperative family equilibrium is analogous to the voluntary provision of public goods model analyzed by Bergstrom et al. (1986). As one might expect, public goods are undersupplied in this noncooperative equilibrium, and there are potential gains to cooperation. Additional gains can be expected if coordination of individual contributions is required for efficient household production. In the absence of cooperation and coordination, the effective quantity of public goods and services such as meals and child care will be less than the amounts that could be produced from the individual contributions."

${ }^{11} \theta_{i}$ may also embody the effort with which the fixed resource $Y_{i}$ is applied towards a cooperative activity.

12 More generally, the gains to cooperation function $G(\cdot)$ is net of any monitoring or transactions costs associated with the cooperation process. Note that the benefits from cooperation represent utility gains from the consumption of a higher quantity of household public goods provided under cooperation.
}

where $0 \leq \theta_{i} \leq 1$, and $0 \leq \delta_{i} \leq 1, i=h, w$. The weights $\delta_{i}$ represent the preference of person $i$ for the cooperation benefits relative to discretionary income. Thus, in deciding how much to contribute towards cooperation, individuals must weigh the benefits of increasing their contribution to the household pool against the forgone benefit of allocating that additional income independently.

Each person then chooses the contribution that maximizes his or her total payoff. The first-order conditions represent reaction functions, i.e., each person's best response given the spouse's actions. The Cournot-Nash equilibrium is given by the intersection of the two reaction functions.

This model is similar to a conventional noncooperative bargaining model in many ways. Cooperation is possible and can yield potential benefits. Under cooperation, income is pooled and jointly allocated according to the bargaining strengths of individuals. Noncooperation is also possible, under which individuals can allocate their income independently. In this model, restricting the contributions such that $\theta_{i}=\{0,1\}$ yields outcomes equivalent to those obtained in a noncooperative bargaining model. Thus, the key difference between this model and the noncooperative bargaining model is that $\theta_{i}$ can take on a range of values, $0 \leq \theta_{i} \leq 1$, and therefore the gains from cooperation may also vary.

From this simple model, it is clear that the resulting income pooling outcome depends largely on the characteristics of the function $G(\cdot)$. The nature of the areas of cooperation within the household as well as the social norms and institutions that govern the cooperation process will determine the degree to which couples will pool their income and cooperate. In the next section, this framework is applied to a situation where the couple can cooperate in saving for adverse shocks. The example of savings is chosen specifically because partial savings pooling has been observed by researchers in a number of specialized surveys (Anderson and Baland, 2002; Ashraf, 2009).

\subsection{Example: saving for a rainy day}

Consider a couple in a low-income developing country context where insurance and credit markets are imperfect. Thus, selfinsurance through precautionary savings is an important strategy for dealing with unexpected adverse events (e.g., natural calamities, accidents, theft, etc.). Any savings held by individuals that is shared with the household when bad shocks occur can therefore be viewed as a household public good. For simplicity, assume that the interest rate is zero.

Suppose that saving for emergencies is the only area of cooperation that can yield potential benefits to the couple. ${ }^{13}$ For example, consider the possibility of a bad storm damaging the roof of the house and causing it to leak. Since this unexpected event affects the entire household, both individuals will be expected to make a contribution towards fixing the roof. Setting aside a fund that the couple could draw on for such emergencies therefore yields potential benefits, relative to the situation where each would have to reallocate their discretionary spending as the need arises. In this context, it is reasonable to assume that increasing one person's contribution, holding the other spouse's contribution constant, yields positive but diminishing benefits. It is also reasonable to assume decreasing returns to scale, e.g., doubling both individuals' contributions yields less than double the increase in benefits.

For couples, cooperation can also be a source of emotional connection and an expression of caring. Individual contributions to a joint savings fund may be valued for the effort it embodies, in

\footnotetext{
13 Assume that all other household public goods are provided noncooperatively, such that individuals specialize in the provision of those public goods that fall in
} their traditional gendered sphere of influence (Lundberg and Pollak, 1993). 
addition to its material worth. Couples may therefore enjoy benefits from joint saving that go beyond the practical act of saving for a rainy day. If indeed the willingness to contribute to joint savings by one partner is taken to be an expression of caring and harmony, then the other spouse may be more willing to reciprocate and contribute more as well, at the very least out of respect or a sense of familial obligation (Badgett and Folbre, 1999).

The gains from cooperation can therefore be represented by the Cobb-Douglas function:

$G\left(\theta_{h} Y_{h}, \theta_{w} Y_{w}\right)=A\left(\theta_{h} Y_{h}\right)^{\alpha}\left(\theta_{w} Y_{w}\right)^{\beta}$

where the benefits depend on the savings pooling contributions $\theta_{h} Y_{h}$ and $\theta_{w} Y_{w}$. The parameters $A, \alpha$ and $\beta$ are positive constants such that $0<\alpha, \beta<1$ and $\alpha+\beta<1$. Thus, the gains from cooperation exhibits positive but diminishing returns to the contributions of individuals and decreasing returns to scale. The parameters $\alpha$ and $\beta$ represent the benefit elasticities of the contributions of the husband and wife, respectively. On the other hand, the parameter $A$ can represent other factors that could shift the net benefits from joint saving. These factors can include, but need not be limited to, the physical and social infrastructure that influence the frequency and severity of adverse shocks, the availability and characteristics of local financial institutions, as well as social norms that govern how men and women share financial information.

If some cooperation does take place, $\theta_{h}>0$ and $\theta_{w}>0$, the couple allocate the pooled savings jointly according to an exogenous sharing rule, $0 \leq \mu \leq 1$. The sharing rule summarizes the extent to which each person's preferences are reflected in how the savings are used and therefore reflects the relative bargaining strengths of individuals. For example, couples may disagree on which shocks take precedence. Should a larger share of the funds be spent on fixing the roof, or in replacing a broken stove? In the extreme case where $\mu=1$ or $\mu=0$, one spouse is able to dictate his or her preferences over how the pooled resources will be used and is therefore able to capture all the benefits from cooperation. The spouse whose preferences are ignored cannot enjoy the material and psychic benefits from cooperation.

Assuming that $\mu$ is the husband's share, contributing $\theta_{h} Y_{h}$ and $\theta_{w} Y_{w}$ to the pooled savings account yields payoffs of $\mu A\left(\theta_{h} Y_{h}\right)^{\alpha}\left(\theta_{w} Y_{w}\right)^{\beta}$ and $(1-\mu) A\left(\theta_{h} Y_{h}\right)^{\alpha}\left(\theta_{w} Y_{w}\right)^{\beta}$ for the husband and wife, respectively. Substituting Eq. (3) into Eqs. (1) and (2) yields the following total payoff functions:

$$
\begin{aligned}
& \mathrm{H}: \pi_{h}=\delta_{h} \mu A\left(\theta_{h} Y_{h}\right)^{\alpha}\left(\theta_{w} Y_{w}\right)^{\beta}+\left(1-\delta_{h}\right)\left(1-\theta_{h}\right) Y_{h}, \\
& \mathrm{~W}: \pi_{w}=\delta_{w}(1-\mu) A\left(\theta_{h} Y_{h}\right)^{\alpha}\left(\theta_{w} Y_{w}\right)^{\beta}+\left(1-\delta_{w}\right)\left(1-\theta_{w}\right) Y_{w} .
\end{aligned}
$$

Each individual must then choose the contribution that yields the highest total payoff subject to his or her budget constraint, $\theta_{i} \leq 1$. The individual maximization problem is given by:

$\max _{\theta_{i}} \pi_{i} \quad$ s.t. $\theta_{i} \leq 1, \quad i=h, w$.

Assuming interior solutions, the first-order conditions are: ${ }^{14}$

$\mathrm{H}: \theta_{h}=\frac{1}{Y_{h}}\left(\frac{\delta_{h}}{\left(1-\delta_{h}\right)} \alpha \mu A\left(\theta_{w} Y_{w}\right)^{\beta}\right)^{1 /(1-\alpha)}$,

\footnotetext{
14 If the budget constraint binds for one partner, such that she contributes her ful income, the equilibrium outcome is obtained by substituting the maximum contribution in the spouse's reaction function. Note that full cooperation by one spouse does not guarantee full cooperation by the other. In the trivial case where one person's optimal contribution is zero, no gains will be realized and therefore neither spouse will contribute. This latter case yields the noncooperative outcome.
}

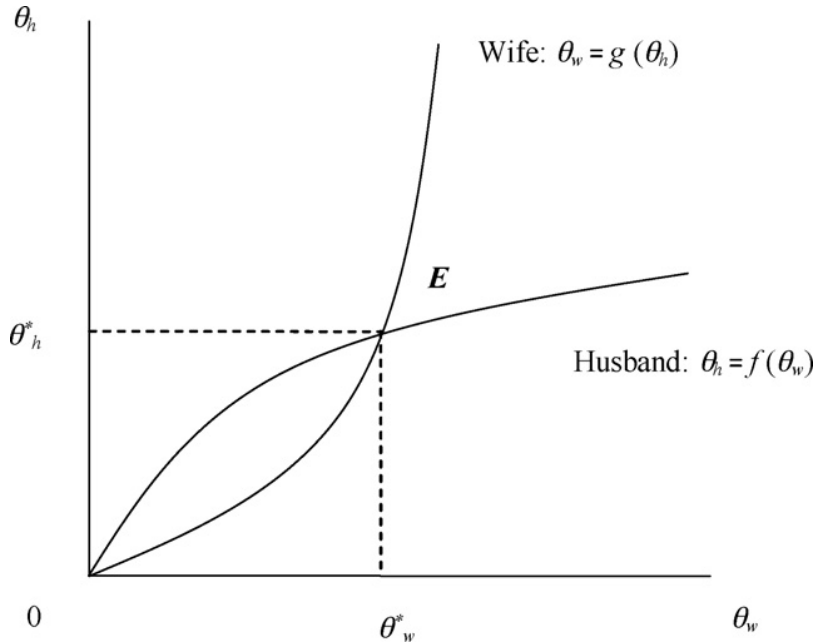

Fig. 1. Reaction functions.

$\mathrm{W}: \theta_{w}=\frac{1}{Y_{w}}\left(\frac{\delta_{w}}{\left(1-\delta_{w}\right)} \beta(1-\mu) A\left(\theta_{h} Y_{h}\right)^{\alpha}\right)^{1 /(1-\beta)}$

These first-order conditions are best response or reaction functions, representing the optimal contribution $\theta_{i}$ for every possible contribution of the spouse $\theta_{j}, i \neq j$. The Cournot-Nash equilibrium is given by the intersection of these two reaction functions, i.e., when both spouses choose mutual best responses. Fig. 1 shows the individual reaction functions and the resulting equilibrium, point E.

Solving for $\theta_{h}$ and $\theta_{w}$ simultaneously using Eqs. (7) and (8) yields the following equilibrium contributions:

$$
\begin{aligned}
& \mathrm{H}: \theta_{h}^{*}=\frac{1}{Y_{h}}\left[A\left(\frac{\delta_{h} \alpha \mu}{1-\delta_{h}}\right)^{1-\beta}\left(\frac{\delta_{w} \beta(1-\mu)}{1-\delta_{w}}\right)^{\beta}\right]^{1 /(1-\alpha-\beta)}, \\
& \mathrm{W}: \theta_{w}^{*}=\frac{1}{Y_{w}}\left[A\left(\frac{\delta_{w} \beta(1-\mu)}{1-\delta_{w}}\right)^{1-\alpha}\left(\frac{\delta_{h} \alpha \mu}{1-\delta_{h}}\right)^{\alpha}\right]^{1 /(1-\alpha-\beta)} .
\end{aligned}
$$

The solutions given by Eqs. (9) and (10) show that there are four sets of factors that influence the shares of income spouses will contribute to the joint savings account: own income, relative bargaining power $\mu$, the benefits from the cooperation process as determined by the parameters $\alpha, \beta$, and $A$, and the preferences of individuals given by the parameters $\delta_{h}$ and $\delta_{w}$.

\subsection{Comparative statics}

From Eqs. (9) and (10), it is clear that the share of income that a person will contribute to joint savings is inversely related to his or her own income and are independent of the spouse's income. For example, Fig. 2 shows the effect of an increase in the wife's income. The result is that the wife's reaction function shifts to the left, so that for every share chosen by her husband, she will contribute a smaller share of her income to the savings pool. On the other hand, the husband's reaction function shifts up such that his contribution will remain unchanged in equilibrium, while the wife's share will decrease to $\theta_{w}^{* *}$. This result is to be expected since the benefits from cooperation depend on the absolute contributions. 


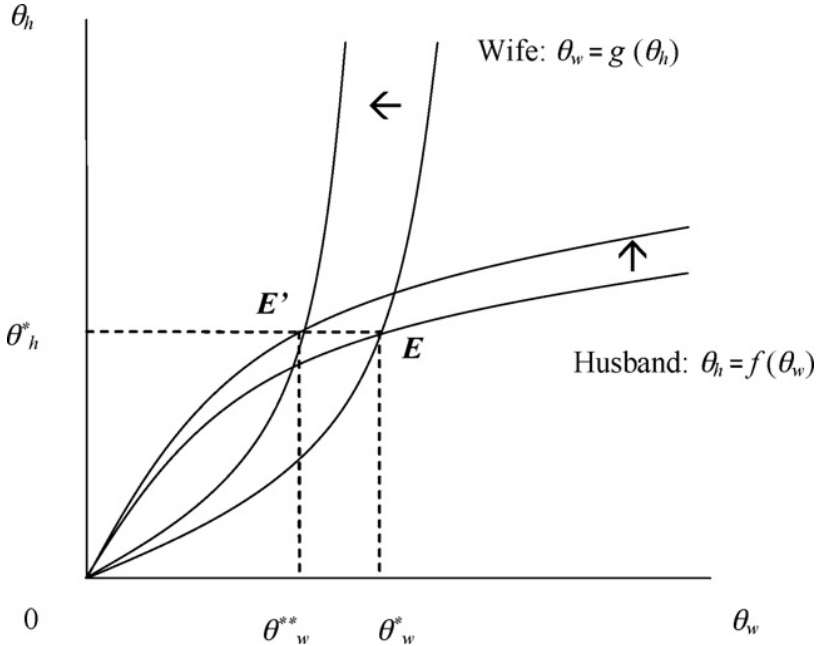

Fig. 2. Effect of an increase in $Y_{w}$.

Formally, the comparative static effects of own income are given by the following:

$$
\begin{aligned}
& \frac{\partial \theta_{h}^{*}}{\partial Y_{h}}=-\frac{1}{Y_{h}^{2}}\left[A\left(\frac{\delta_{h} \alpha \mu}{1-\delta_{h}}\right)^{1-\beta}\left(\frac{\delta_{w} \beta(1-\mu)}{1-\delta_{w}}\right)^{\beta}\right]^{1 /(1-\alpha-\beta)}<0, \\
& \frac{\partial \theta_{w}^{*}}{\partial Y_{w}}=-\frac{1}{Y_{w}^{2}}\left[A\left(\frac{\delta_{w} \beta(1-\mu)}{1-\delta_{w}}\right)^{1-\alpha}\left(\frac{\delta_{h} \alpha \mu}{1-\delta_{h}}\right)^{\alpha}\right]^{1 /(1-\alpha-\beta)}<0 .
\end{aligned}
$$

and the comparative static effects of the partner's income is given by $\partial \theta_{h}^{*} / \partial Y_{w}=\partial \theta_{w}^{*} / \partial Y_{h}=0$.

The comparative static effect of relative bargaining power is less straightforward. Looking at the reaction functions in Eqs. (7) and (8), it is clear that each person's best response increases with their own bargaining power. Therefore, an increase in $\mu$ will shift the husband's reaction function outwards, and at the same time shift the wife's reaction function inwards. The net effect on the equilibrium outcome will depend on which shift dominates. Taking the partial derivative of the equilibrium solutions $\theta_{h}^{*}$ and $\theta_{w}^{*}$ with respect to $\mu$ yields the following signs:

$$
\begin{aligned}
\frac{\partial \theta_{h}^{*}}{\partial \mu} \gtreqless 0 \text { if } \frac{1-\mu}{\mu} \gtreqless \frac{\beta}{1-\beta}, \\
\frac{\partial \theta_{w}^{*}}{\partial \mu} \gtreqless 0 \text { if } \frac{1-\mu}{\mu} \gtreqless \frac{1-\alpha}{\alpha} .
\end{aligned}
$$

Given $\alpha$ and $\beta$, the comparative static effect of increasing the relative bargaining power of the husband depends on the existing balance of power. Increasing the bargaining power of one party is more likely to encourage cooperation, i.e., both spouses contribute more, if that party was initially disadvantaged. So moving from a high degree of inequality towards more equality increases cooperation, consistent with Pahl's (1995) findings that egalitarian couples are more likely to pool and jointly manage their money. ${ }^{15}$

\footnotetext{
15 Specifically, the more dominant the husband is (as $\mu \rightarrow 1$ ), the more likely that $\partial \theta_{h}^{*} / \partial \mu<0$ and $\partial \theta_{w}^{*} / \partial \mu<0$. So both husband and wife will pool a lower share of their income as the husband gains even more bargaining power, i.e., as $\mu \uparrow$, and both husband and wife will pool a higher share of their income as the wife gains more bargaining power, i.e., as $\mu \downarrow$. Conversely, the more dominant the wife is (as $\mu \rightarrow 0$ ), the more likely that $\partial \theta_{h}^{*} / \partial \mu>0$ and $\partial \theta_{w}^{*} / \partial \mu>0$. So when it is the wife who initially has the bargaining advantage, increasing the husband's relative bargaining power will result in both individuals contributing larger shares of their income towards cooperation, and increasing the wife's bargaining power even more will result in both individuals contributing smaller shares of their income towards cooperation.
}

Suppose that the husband initially has the bargaining advantage so that his preferences dominate how joint savings are allocated, and that both spouses cooperate partially $\left(0<\theta_{i}<1\right)$. An increase in the wife's bargaining power will increase her share of the gains from joint saving and therefore she will be willing to increase her contribution. An increase in her contribution increases the husband's gains as well. So long as this increase in the husband's gains more than offsets his loss from the decline in his relative bargaining power, he will reciprocate and contribute more. On the other hand, any additional increases in the husband's bargaining power will further reduce the benefits from joint saving enjoyed by the wife. She will then reduce her contribution, the overall gains from joint saving contracts, reducing the benefits the husband enjoys, and so he too will reduce his contribution.

But what happens if the existing balance of power is already equal, i.e., $\mu=1 / 2$ ? In this case, the comparative static effect of moving away from equality depends solely on the benefit elasticity of the other spouse's contribution to joint savings. Therefore, the change in the husband's contribution depends on $\beta$, and the change in the wife's contribution depends on $\alpha$. This yields the following signs:

$$
\begin{gathered}
\frac{\partial \theta_{h}^{*}}{\partial \mu} \gtreqless 0 \text { if } \quad \frac{1}{2} \gtreqless \beta, \\
\frac{\partial \theta_{w}^{*}}{\partial \mu} \gtreqless 0 \text { if } \quad \alpha \gtreqless \frac{1}{2} .
\end{gathered}
$$

Suppose that initially the spouses have equal bargaining power $(\mu=1 / 2)$, and that both spouses cooperate partially $\left(0<\theta_{i}<1\right)$. An increase in the husband's bargaining power $(\mu \uparrow)$ will increase both spouses' contribution to joint savings if the husband's benefit elasticity is high $(\alpha>1 / 2)$ and the wife's benefit elasticity is low $(\beta<1 / 2)$. This result is intuitive: the spouse whose contribution is more productive, given by the high benefit elasticity, will be inclined to contribute even more when his bargaining power is increased. An increase in the husband's contribution increases the wife's gains as well. So long as the increase in the wife's gains more than offsets her loss from the decline in her bargaining power, she will reciprocate and contribute more. On the other hand, if the benefit elasticities are reversed so that the husband's benefit elasticity is low $(\alpha<1 / 2)$ and the wife's benefit elasticity is high $(\beta>1 / 2)$, increasing the husband's relative bargaining power (i.e., decreasing the wife's bargaining power) will decrease both spouses' contributions. In this case, the spouse whose contribution to joint savings is more productive will be inclined to reduce her contribution when her bargaining power is decreased. This in turn also reduces the husband's gains, and he will also decrease his contribution. ${ }^{16}$

Lastly, the comparative static effects of $A$ can be easily deduced from Eqs. (9) and (10). Factors that increase the overall benefits from cooperation will encourage income pooling, increasing the equilibrium contributions from both spouses. The effect of increasing $A$ is illustrated in Fig. 3, where both spouses increase their equilibrium contributions to point $E^{\prime}=\left(\theta_{w}^{* *}, \theta_{h}^{* *}\right)$.

Formally, the comparative static effects of $A$ are given by the following:

$$
\frac{\partial \theta_{h}^{*}}{\partial A}=\left(\frac{c_{h}}{1-\alpha-\beta}\right) A^{(\alpha+\beta) /(1-\alpha-\beta)}>0
$$

\footnotetext{
${ }^{16}$ In the case of precautionary savings, it is not clear that one spouse would have an advantage in producing more gains by contributing to the household pool. There could be, however, other areas of cooperation where asymmetric benefit elasticities are plausible. For example, in countries where women grow subsistence crops and men grow cash crops, women's contributions may be more effective in ensuring
} food security for the household because it is not tied to market fluctuations. 


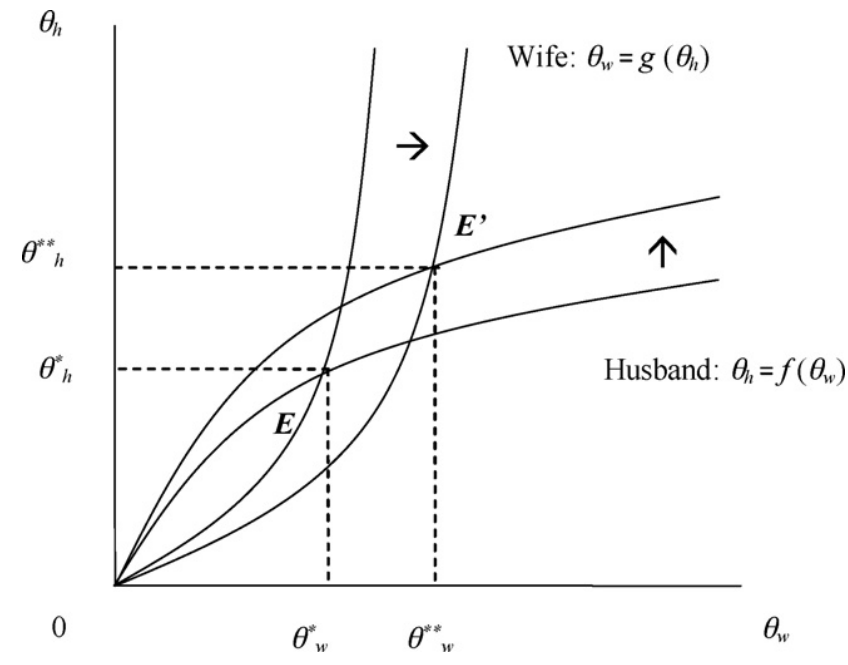

Fig. 3. Effect of an increase in A.

$\frac{\partial \theta_{w}^{*}}{\partial A}=\left(\frac{c_{w}}{1-\alpha-\beta}\right) A^{(\alpha+\beta) /(1-\alpha-\beta)}>0$

where $c_{h}$ and $c_{w}$ are positive constants.

When both partners contribute their full income to joint savings, $\theta_{w}^{*}=\theta_{h}^{*}=1$, the contributions become public information and so no income can be hidden. Therefore, the hiding of income can only occur under partial income pooling or nonpooling, i.e., $0 \leq \theta_{w}^{*}, \theta_{h}^{*}<1$. Because hidden income implies noncooperation, the conditions that reduce contributions to joint savings, and thus increase discretionary income, create opportunities for hiding income. Nevertheless, noncooperation by itself does not provide an incentive to hide financial information. To explore these incentives further, another dimension of power is introduced in the model.

\subsection{Limited autonomy}

The model so far assumes that both individuals have the ability to choose how much of their income they wish to devote to cooperation. This may not always be the case, however; social and gender norms could assign the right to choose the share of income to be contributed by the couple to either the husband only or the wife only. For example, many cultures assign men as the traditional head of the household, which could suggest that wives are compelled to comply with what their husbands deem as the appropriate contribution. This is akin to what Pahl (1983) refers to as control, which is the decision making power over the type of allocative system the household should adapt. Ethnographic evidence suggests that the patriarchal regime is the norm among households in slum areas in Kenya (Anderson and Baland, 2002), people from Upper Egypt (Hoodfar, 1988), the Yoruba people in Nigeria (Fapohunda, 1988), and the Beti poeple in Cameroon (Guyer, 1988). On the other hand, some cultures assign women as the traditional pursekeepers or money managers of the household, as observed by researchers in Indonesia (Papanek and Schwede, 1988), the Philippines (Aguilar, 1991; Ashraf, 2009), and Thailand (Nguanbanchong, 2004). This norm may confer to women the authority to demand what they deem as the appropriate contribution from their husbands.

These cases can be accommodated in the model by restricting the assumption of autonomy to apply only to one spouse and not the other. Imposing this restriction therefore adds another dimension of power in the model in addition to bargaining power.

\subsubsection{Patriarchal regime}

Suppose that the husband has the sole authority to choose the income share to be contributed by both husband and wife to the joint savings pool. Assume also that his choice is enforceable, i.e., his wife is compelled to contribute the appropriate amount he demands. Therefore, the husband chooses the share that maximizes his payoff, and then the wife follows the husband's lead and contributes the same proportion of her income. Using the previous specification of the cooperation gains, the husband's maximization problem is given by:

$\max _{\theta_{P}} \pi_{h}=\delta_{h} \mu A \theta_{P}^{\alpha+\beta} Y_{h}^{\alpha} Y_{w}^{\beta}+\left(1-\delta_{h}\right)\left(1-\theta_{P}\right) Y_{h}$,

and the first-order condition is given by:

$\frac{(\alpha+\beta) \delta_{h} \mu A Y_{h}^{\alpha} Y_{w}^{\beta}}{\theta_{P}^{1-\alpha-\beta}}=\left(1-\delta_{h}\right) Y_{h}$.

The optimal degree of cooperation under the patriarchal regime is:

$\theta_{P}^{*}=\left[\frac{(\alpha+\beta) \delta_{h} \mu A Y_{w}^{\beta}}{\left(1-\delta_{h}\right) Y_{h}^{1-\alpha}}\right]^{1 /(1-\alpha-\beta)}$,

which is increasing in the wife's income, decreasing in the husband's income, and increasing in the husband's bargaining power.

\subsubsection{Matriarchal regime}

Conversely, suppose that the wife has the sole authority to choose the income share to be contributed by both husband and wife. Again, assume that her choice is enforceable, i.e., her husband is compelled to contribute the appropriate amount she demands. The wife's maximization problem is therefore given by:

$\max _{\theta_{M}} \pi_{w}=\delta_{w}(1-\mu) A \theta_{M}^{\alpha+\beta} Y_{h}^{\alpha} Y_{w}^{\beta}+\left(1-\delta_{w}\right)\left(1-\theta_{M}\right) Y_{w}$,

and the first-order condition is given by:

$\frac{(\alpha+\beta) \delta_{w}(1-\mu) A Y_{h}^{\alpha} Y_{w}^{\beta}}{\theta_{M}^{1-\alpha-\beta}}=\left(1-\delta_{w}\right) Y_{w}$.

The optimal degree of cooperation under the matriarchal regime is:

$\theta_{M}^{*}=\left(\frac{(\alpha+\beta) \delta_{w}(1-\mu) A Y_{h}^{\alpha}}{\left(1-\delta_{w}\right) Y_{w}^{1-\beta}}\right)^{1 /(1-\alpha-\beta)}$,

which is increasing in the husband's income, decreasing in the wife's income, and increasing in the wife's bargaining power.

\subsection{Discussion}

In the household regimes described above, there are two particular results that differ from the case of individual autonomy. First, the equilibrium degree of cooperation $\theta_{P}^{*}$ and $\theta_{M}^{*}$ depend on both spouses' incomes, whereas under individual autonomy only one's own income mattered. An increase in income of the non-deciding spouse would have reduced that spouse's contribution under individual autonomy. But under limited autonomy, the partner who does decide will want to increase the degree of cooperation in the household to be able to share the benefits from the higher income from the non-deciding spouse.

Second, the comparative static effect of relative bargaining power is no longer ambiguous. The degree of cooperation in the household will be increasing in the deciding spouse's bargaining power. Thus, increasing women's bargaining power within a patriarchal regime will result in a lower share of income pooled by both the husband and the wife. When the wife has more influence in how 
the joint savings account will be used, the cooperation benefits realized by the husband is reduced. Consequently, he will decrease his contribution and his wife follows suit.

Conversely, increasing women's bargaining power within a matriarchal regime will result in more income pooling for both spouses. Increasing the wife's bargaining power implies that she is better able to influence the allocation of the joint resources towards her preferences and is thus able to capture a larger share of the cooperation gains. Under a matriarchal regime, the wife will then choose to contribute a higher share of her income to the household pool and demand the same higher share from her husband.

Given that men tend to earn higher incomes on average compared to women (Blau and Kahn, 2003; International Labour Organisation, 2009), under which regime can one expect to observe more income pooling? This model predicts that, the higher the income gap between the husband and wife, the more likely that the couple will pool more income under a matriarchal regime. This result is intuitive. If the husband earns significantly more than the wife, and the wife has the sole authority to choose the contributions, the wife will demand a larger contribution from the husband to be able to share in the benefits of that income. Comparing the two solutions yields the following condition:

$\theta_{M}^{*}>\theta_{P}^{*} \quad$ if $\frac{Y_{h}}{Y_{w}}>\frac{\mu \delta_{h}\left(1-\delta_{w}\right)}{(1-\mu)\left(1-\delta_{h}\right) \delta_{w}}$.

This result suggests that conventional household surveys that implicitly assume full income pooling are more likely to miss more information in populations where a patriarchal household regime is the norm, compared to populations where a matriarchal regime is more common. More generally, however, limited autonomy can create incentives for the non-deciding partners to conceal income from their spouses if they are compelled to contribute a higher share than they would prefer if they had the choice.

Under a patriarchal regime, the wife has an incentive to hide income if the contribution demanded by the husband, $\theta_{P}^{*}$, is greater than the optimal income share she would choose to contribute if she could decide for herself, $\theta_{w}^{*}$. Comparing the two solutions yields the following condition:

$\theta_{P}^{*}>\theta_{w}^{*} \quad$ if $\frac{\mu}{(1-\mu)}>\frac{Y_{h}}{Y_{w}} \frac{\beta \delta_{w}\left(1-\delta_{h}\right)}{\delta_{h}\left(1-\delta_{w}\right)}\left(\frac{\alpha^{\alpha}}{\alpha+\beta}\right)^{1 /(1-\alpha)}$.

So given a patriarchal regime, the wife is more likely to have an incentive to hide income as the husband's bargaining power rises, and as her own income rises. Conversely, the wife is less likely to hide income as her own bargaining power rises, and as her income falls. This result is consistent with Anderson and Baland's (2002) observation that married women who participate and therefore save secretly in ROSCAs have higher individual incomes on average compared with non-participants. They argue that the primary reason women seek to hide their savings from their husbands is the asymmetry of preferences, where women value household public goods more than men. But conflicting preferences in itself would not lead women to hide their income if they had enough bargaining power in the household. Thus, the role of power, which comes through very clearly in Anderson and Baland's (2002) ethnographic interviews, is made more explicit in this model, where the interaction of both autonomy and bargaining power could explain the need of women to hide their savings. In the case where the husband is completely dominant, i.e., $\mu \rightarrow 1$ as in a unitary model, the wife's incentive to hide income will be very high. Therefore, collecting data from the husband alone, even in the case of a dictatorship, will potentially miss any financial information hidden by the wife.

Similarly, the husband under a matriarchal regime has an incentive to hide income if the contribution demanded by the wife, $\theta_{M}^{*}$, is greater than the optimal share he would choose to contribute if he could decide for himself, $\theta_{h}^{*}$. Comparing the two solutions yields the following condition:

$\theta_{M}^{*}>\theta_{h}^{*} \quad$ if $\frac{(1-\mu)}{\mu}>\frac{Y_{w}}{Y_{h}} \frac{\alpha \delta_{h}\left(1-\delta_{w}\right)}{\delta_{w}\left(1-\delta_{h}\right)}\left(\frac{\beta^{\beta}}{\alpha+\beta}\right)^{1 /(1-\beta)}$.

So given a matriarchal regime, the husband is more likely to have an incentive to hide income as the wife's bargaining power rises, and as his own income rises. It follows that the husband is less likely to hide income as his own bargaining power rises, and as his own income falls. This result appears to be consistent with Ashraf's (2008) findings regarding the effect of a positive income shock on saving behavior in the Philippines. She reports that among the men whose wives make the savings decisions in the household (a matriarchal regime), men are more likely to save the windfall income into their own account when their wives will not be informed of their decision, and are more likely to commit it to personal consumption when their wives will be informed (Ashraf, 2009). She also finds similar behavior among women whose husbands make the household savings decisions (a patriarchal regime) (Ashraf, 2009). As noted above, wives are more likely to have an incentive to hide income as their own income rises under a patriarchal regime.

The relative taste for cooperation $\left(\delta_{i}\right)$ can also contribute to the incentive to hide income. As might be expected, the non-deciding spouse is more likely to hide income if the deciding spouse's taste for cooperation is stronger than their own. So under a matriarchal regime, if the wife has a stronger preference for cooperation than the husband $\left(\delta_{w}>\delta_{h}\right)$, then the husband will be more likely to hide income. Given these same preferences, there will be less incentive for the wife to hide income under a patriarchal regime, since the optimal contribution chosen by the husband is unlikely to exceed his wife's own desired contribution.

Note that the incentive to hide income can exist in both regimes even when bargaining power is equal, $\mu=1 / 2$. Equal power implies that the preferences of both husband and wife are equally reflected in the allocation of joint savings and so they also share equally in the benefits from cooperation. Nevertheless, income asymmetries could still create incentives for hiding income. A high-earning wife in a patriarchal regime and a high-earning husband in a matriarchal regime may not wish to contribute as much as their partner demands, even with equal bargaining power. In both these cases, there will be an incentive for the non-deciding spouse to hide income.

All these results depend largely on the characteristics of the $G(\cdot)$ function. In the example of precautionary savings adopted here, the gains from cooperation is specified as a Cobb-Douglas function. However, applying this model to a different context of cooperation that exhibits different characteristics in terms of returns to scale, marginal benefits and marginal cross-benefits is likely to yield a different set of results. Thus, how researchers conceptualize the areas of cooperation within the household is crucial in predicting the income pooling behavior of couples. To further guide economists in unraveling the black box of intrahousehold behavior, more qualitative and quantitative information should be collected regarding the process of cooperation within households.

\section{Conclusions}

The model developed in this paper combines features of noncooperative bargaining models (Lundberg and Pollak, 1993; Carter and Katz, 1997; Konrad and Lommerud, 2000; Chen and Wooley, 2001) and collective models (Chiappori, 1988, 1992, 1997; Quisumbing and Maluccio, 2003) to demonstrate the semicooperative character of household financial decision making. Noncooperative bargaining models use the noncooperative equilibrium as the threat point in a cooperative bargaining game. The 
outcome is either cooperation, if the utility gains from cooperation are sufficient, or noncooperation, if the threat points offer more utility. In contrast, the model introduced here recognizes that cooperative and noncooperative behavior within households need not be mutually exclusive. The key innovation of this approach is to characterize individuals' decision to cooperate as a continuous variable, defined by the share of income they choose to contribute to the household pool.

Applied to the example of saving as an area of household cooperation, this model predicts that the equilibrium contributions to the joint savings account is decreasing in own income and increasing in other factors that can shift the overall benefits of saving jointly. These factors can include physical and social infrastructure, the characteristics of local financial institutions, as well as social norms that govern how men and women share financial information. However, the relationship between the joint savings contributions and relative bargaining power depend on the initial balance of power. In particular, increasing the bargaining power of one partner is more likely to result in higher savings pooling only if that person was initially disadvantaged. This is also consistent with Pahl's (1995) findings that egalitarian couples are more likely to pool and jointly manage their money.

In addition to the concept of bargaining power within a cooperative setting, another dimension of power can be imposed on the model by restricting individual autonomy to apply to only one spouse. Limited autonomy can create incentives for the nondeciding partners to conceal income from their spouses if they are compelled to contribute a higher share than they would prefer if they had the choice. When the husband has the authority to decide on both spouses' joint saving contributions, the wife is more likely to have an incentive to hide income as the husband's bargaining power rises, and as her own income rises. Conversely, when it is the wife who holds that authority, the husband is more likely to have an incentive to hide income as the wife's bargaining power rises, and as his own income rises. These observations appear to be consistent with the findings of Ashraf (2009) in the Philippines, where a positive income shock is more likely to be hidden by husbands in matriarchal regimes and by wives in patriarchal regimes.

Also, the larger the gap between male and female incomes, the more likely that a matriarchal regime will exhibit a higher degree of savings pooling relative to a patriarchal regime. Since women continue to earn lower incomes on average compared with men (Blau and Kahn, 2003; International Labour Organisation, 2009), this result suggests that conventional household surveys that implicitly assume full income pooling are more likely to miss more information in populations where a patriarchal household regime is the norm, compared to populations where a matriarchal regime is more common.

This model reinforces the issues raised by noncooperative household models on traditional survey methodology, thus providing further theoretical support for the call to collect survey data from individuals rather than household representatives. If individuals deliberately conceal income from their spouse to avoid pooling that income, then the private information missed by traditional surveys will be nonrandom and may significantly bias empirical analyses that use household income as a regressor (Ashraf, 2009). Furthermore, if the contributions to the household pool depend on bargaining power, as this model suggests, then this could result in significant collinearity between the proxy measures of bargaining power and pooled household income. Both issues can be addressed by collecting financial data from individuals in separate interviews, which better captures any private information withheld by the individual from the rest of the household.

Although this model's assumptions are plausible, as corroborated by the interdisciplinary evidence on this subject, whether the optimal conditions implied by the model actually hold in reality is an empirical question that merits further study. To answer this question, more detailed information on decision making processes, the nature of cooperation, and information sharing practices within the household must be collected in addition to individual financial information.

\section{Acknowledgments}

I am grateful to Maria S. Floro, Mieke Meurs, Amos Golan, James Bono, Caren Grown, Mary Hansen, Hitomi Komatsu, Lina Salazar, Michael Martell, and Fatma Gul Unal for their helpful comments.

\section{References}

Agarwal, B., 1997. Bargaining and gender relations: within and beyond the household. Feminist Economics 3 (1), 1-51.

Aguilar, D.D., 1991. Filipino Housewives Speak. Institute of Women's Studies, St. Scholastica's College, Metro Manila.

Alderman, H., Chiappori, P.-A., Haddad, L., Hoddinott, J., Kanbur, R., 1995. Unitary versus collective models of the household: is it time to shift the burden of proof? The World Bank Research Observer 10 (1), 1-19.

Allianz, 2006. Women, money and power. Allianz Life Insurance Company of North America, Press Release, August 22, 2006.

Anderson, S., Baland, J.-M., 2002. The economics of ROSCAs and intrahousehold resource allocation. The Quarterly Journal of Economics 117 (3), 963-995.

Ashraf, N., 2009. Spousal control and intra-household decision making: an experimental study in the Philippines. The American Economic Review 99 (4), 1245-1277.

Aura, S., 2005. Uncommitted couples: some efficiency and policy implications of marital bargaining. University of Missouri, Columbia, unpublished paper.

Badgett, M.V.L., Folbre, N., 1999. Assigning care: gender norms and economic outcomes. International Labour Review 138 (3), 311-326.

Becker, G., 1981. A Treatise on the Family. Harvard University Press, Massachusetts.

Benería, L., Roldán, M., 1987. The Crossroads of Class and Gender: Industrial Homework, Subcontracting, and Household Dynamics in Mexico City. University of Chicago Press.

Bergstrom, T.C., 1996. Economics in a family way. Journal of Economic Literature 34 (4), 1903-1934.

Bergstrom, T.C., Blume, L., Varian, H., 1986. On the private provision of public goods. Journal of Public Economics 29, 25-49.

Blau, F.D., Kahn, L.M., 2003. Understanding international differences in the gender pay gap. Journal of Labor Economics 21 (1), 106-144.

Carter, M.R., Katz, E.G., 1997. Separate spheres and the conjugal contract: understanding the impact of gender biased development. In: Alderman, H., Hoddinott, J., Haddad, L. (Eds.), Intrahousehold Resource Allocation in Developing Countries: Methods, Models and Policy. Johns Hopkins University Press, Baltimore, pp. 95-111.

Chen, Z., Wooley, F., 2001. A Cournot-Nash model of family decision making. The Economic Journal 111, 722-748.

Chiappori, P.-A., 1988. Rational household labor supply. Econometrica 56 (1), 63-89.

Chiappori, P.-A., 1992. Collective labor supply and welfare. Journal of Political Economy 100 (3), 437-467.

Chiappori, P.-A., 1997. Collective models of household behavior: the sharing rule approach. In: Alderman, H., Hoddinott, J., Haddad, L. (Eds.), Intrahousehold Resource Allocation in Developing Countries: Methods, Models and Policy. Johns Hopkins University Press, Baltimore, pp. 39-52.

Dwyer, D., Bruce, J., 1988. A Home Divided: Women and Income in the Third World. Stanford University Press, Stanford, California.

Elster, J., 1989. Social norms and economic theory. Journal of Economic Perspectives 3, 99-117.

Fapohunda, E.R., 1988. The nonpooling household: a challenge to theory. In: Dwyer D., Bruce, J. (Eds.), A Home Divided: Women and Income in the Third World. Stanford University Press, Stanford, California, pp. 143-154.

Fletschner, D., 2009. Rural women's access to credit: market imperfections and intrahousehold dynamics. World Development 37 (3), 618-631.

Goldstein, M., 1999. Chop time, no friends: intrahousehold and individual insurance mechanisms in Southern Ghana. University of California, Berkeley, unpublished paper.

Goldstein, M., Udry C., 1999. Gender and Land Resource Management in Southern Ghana. Yale University, Working Paper.

Guyer, J., 1988. Dynamic approaches to domestic budgeting: cases and methods from Africa. In: Dwyer, D., Bruce, J. (Eds.), A Home Divided: Women and Income in the Third World. Stanford University Press, Stanford, California, pp. 155-172.

Hoodfar, H., 1988. Household budgeting and financial management in a lowerincome Cairo neighborhood. In: Dwyer, D., Bruce, J. (Eds.), A Home Divided: Women and Income in the Third World. Stanford University Press, Stanford California, pp. 120-142.

International Labour Organisation, 2009. Global Employment Trends for Women. International Labour Organisation (ILO), Geneva.

Katz, E., 1997. The intra-household economics of voice and exit. Feminist Economics 3 (3), 25-46. 
Konrad, K.A., Lommerud, K.E., 2000. The bargaining family revisited. Canadian Journal of Economics 33 (2), 471-487.

Lundberg, S., Pollak, R.A., 1993. Separate spheres bargaining and the marriage market. Journal of Political Economy 101 (6), 988-1010.

Lundberg, S., Pollak, R.A., 2003. Efficiency in marriage. Review of Economics of the Household 1 (3), 153-167.

Manser, M., Brown, M., 1980. Marriage and household decision-making: a bargaining analysis. International Economic Review 21 (1), 31-44.

Mazzocco, M., 2007. Household intertemporal behaviour: a collective characterization and a test of commitment. Review of Economic Studies 74, 857-895.

McElroy, M.B., 1990. The empirical content of Nash-bargained household behavior. Journal of Human Resources 25 (4), 559-583.

McElroy, M.B., 1997. The policy implications of family bargaining and marriage markets. In: Alderman, H., Hoddinott, J., Haddad, L. (Eds.), Intrahousehold Resource Allocation in Developing Countries: Methods, Models and Policy. Johns Hopkins University Press, Baltimore, pp. 53-74.

McElroy, M.B., Horney, M.J., 1981. Nash-bargained household decisions: toward a generalization of a theory of demand. International Economic Review 22 (2), 333-349.

Nguanbanchong, A., 2004. The analysis of gender effects on saving: evidence from urban poor home-based workers in Thailand. PhD diss. American University, Washington, DC
Pahl, J., 1983. the allocation of money and the structuring of inequality within marriage. The Sociological Review 31 (2), 237-262.

Pahl, J., 1989. Money and Marriage. Macmillan, London.

Pahl, J., 1995. His money, her money: recent research on financial organisation in marriage. Journal of Economic Psychology 16, 361-376.

Papanek, H., Schwede, L., 1988. Women are good with money: earning and managing in an Indonesian city. In: Dwyer, D., Bruce, J. (Eds.), A Home Divided: Women and Income in the Third World. Stanford University Press, Stanford, California, pp. 71-98.

Pollak, R.A., 2005. Bargaining power in marriage: earnings, wage rates and household production. National Bureau of Economic Research (NBER), Working Paper 11239.

Quisumbing, A.R., Maluccio, J.A., 2003. Resources at marriage and intrahousehold allocation: evidence from Bangladesh, Ethiopia, Indonesia, and South Africa. Oxford Bulletin of Economics and Statistics 65 (3), 283-327.

Samuelson, P.A., 1956. Social indifference curves. Quarterly Journal of Economics 70

(1), 1-22.
Sugden, R., 1989. Spontaneous order. Journal of Economic Perspectives 3, 85-97.

Whitaker, L., 2004. The secret stash. TIME Magazine, March 1, 2004. 